\title{
Scientific and Technical Substantiation of Reducing Oil Viscosity
}

\author{
G.Zh. Moldabayeva ${ }^{1}$, R.T. Suleimenova ${ }^{1}$, M.F. Turdiyev ${ }^{2}$, Zh.B. Shayakhmetova ${ }^{2}$, A.S. Karimova ${ }^{2}$ \\ ${ }^{1}$ Department of Petroleum Engineering, Satbayev University, Satpayev Ave., 22 -050000, Almaty, Republic of Kazakhstan. \\ ${ }^{2}$ Department of Oil and Gas Business, Atyrau University of Oil and Gas, Baimukhanav St, 45a -060027, Atyrau, Republic of Kazakhstan.
}

\begin{abstract}
:
Ultrasonic technology is a cost-effective and environmentally friendly non-traditional method of enhancing oil recovery, which is of great interest to researchers and field production engineers. The integration of ultrasound with surfactants has been proven to be effective in increasing oil recovery by reducing salt adsorption in the fluid. Many studies focused on the water-oil phase behavior to determine whether ultrasound can actually reduce oil viscosity (fluidity). However, the phase behavior alone cannot answer this question. Therefore, the present study investigated the role of reducing oil viscosity with the use of ultrasound at different intense frequencies. For this purpose, ultrasonic processing of an unconsolidated model with sand placed in an ultrasonic bath was applied. As a result of a laboratory experiment, the viscosity during ultrasonic processing showed a significant decrease to $30 \%$ from the initial value of $138 \mathrm{MPa}^{*}$ s. The change effect was discovered in the physical properties of the studied oil-water compositions in electromechanical field variables of different nature. Based on the results of experimental work, a method was developed and tested for reducing the viscosity of high-paraffin oils. However, in the course of research, several manifestation features of these effects were revealed, suggesting their applicability in the processes of synthesis and destruction of heavy hydrocarbons. In this regard, the relevance of the study consists in the dependence of changes in oil viscosity on the type and parameters of electrophysical effects. The authors conducted a laboratory experiment to reduce viscosity, built a hydrodynamic model to determine its effectiveness for processing a single well, and built a model using COMSOL Multiphysics software. The technology of stimulating oil wells with high-power ultrasound has been applied in various onshore and offshore fields. The developer of this technology takes good care of their customers and maintains confidentiality in relation to linking their performance indicators to a specific field. However, extensive ultrasonic tests have been provided showing that oil production rises from $38 \%$ to $380 \%$ based on average barrel/day flow rates.
\end{abstract}

Keywords - Enhanced Oil Recovery, Viscosity, Hydrodynamic Model, Well, Reservoir, Ultrasound.

\section{INTRODUCTION}

Since the late 20th century, great interest has been paid to using wave action to reduce viscosity. However, currently, there is insufficient information on the effect of wave processing on the rheological properties of formation fluids as well as on the specific mechanism of wave action on the porous medium [1-3]. The effect of wave processing on oil viscosity immediately at the time of radiation as well as on reducing oil viscosity are of potential interest in the oil industry, therefore this problem needs to be studied in more detail [4-7].

The purpose of the study is to develop scientific and technical foundations for reducing viscosity and creating conditions for the transition from traditional methods of oil production to energy-saving methods that provide a significant increase in its extraction.

Ultrasonic technology cleans capillaries of resin, asphaltene and paraffin deposits to increase the oil flow to the well. Paraffins, resins, asphaltenes and other damages clog pores, which is why oil wells are operated with less potential.

The use of ultrasound is the basis of the cleaning mechanism with micro-acoustic currents in the pore space [8-11]. At the same time, high power ultrasound destroys the adhesive forces that hold the particles in place and ensures the subsequent removal of these particles. The pore space and permeability are restored, which leads to an increase in the flow rate.

\section{MATERIAL AND METHODS}

In order to solve these tasks, the following research methods were used:

- $\quad$ analysis and generalization of literary sources and experience;

- $\quad$ physical modeling of electromechanical processes;

- $\quad$ experimental studies on the properties of varieties of fluid-containing compositions depending on changes in the frequency or potential of external influence.

\section{RESULTS}

The rheometer operates according to the Searle principle (rotating concentric cylinders), has a wide range of torque speeds, and is equipped with an engine with a short response time. In addition, the rheometer is equipped with two control systems for fluid heating and cooling, which provide quick and accurate temperature control in the range from $-20^{\circ} \mathrm{C}$ to $+80^{\circ} \mathrm{C}$.

Figs. 1-3 show the equipment used in the laboratory experiment. 


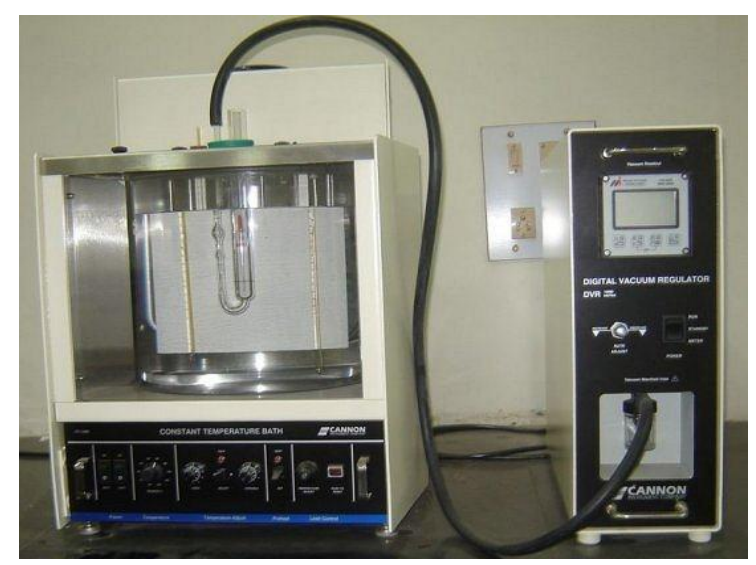

Fig. 1. Equipment used in the laboratory experiment

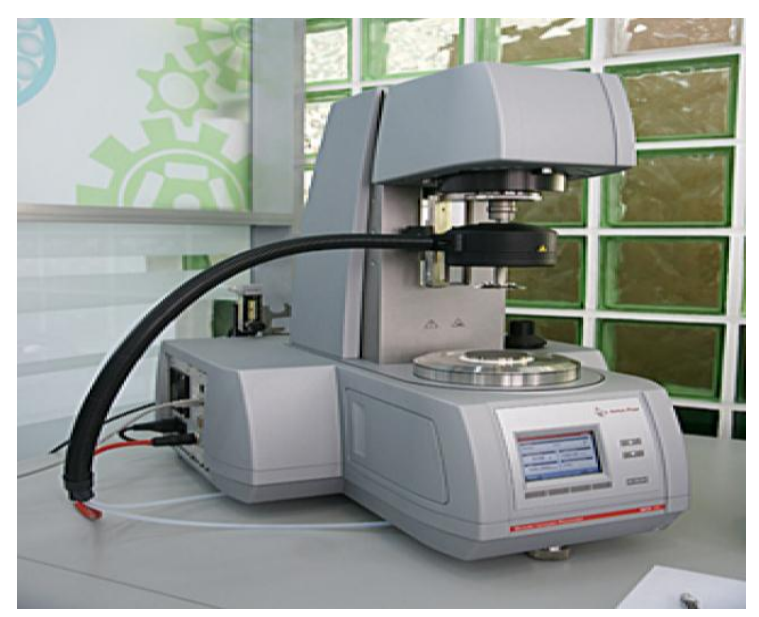

Fig. 2. Equipment used in the laboratory experiment

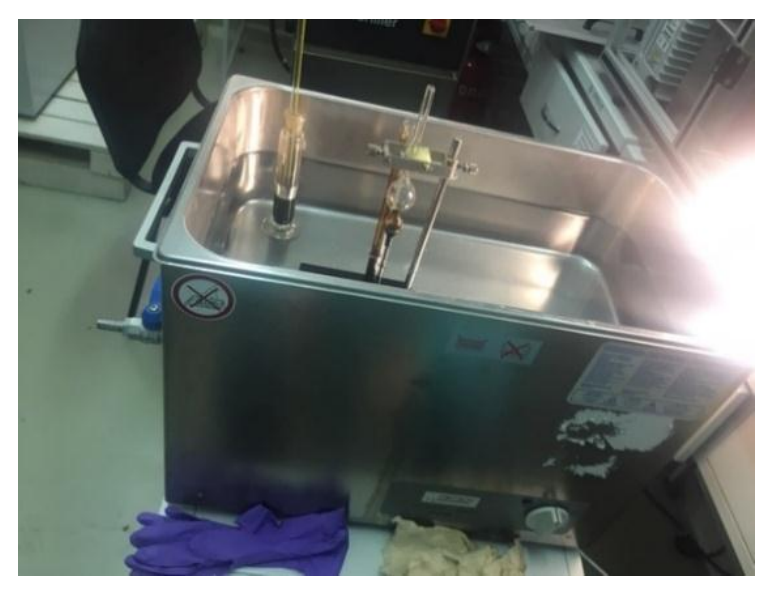

Fig. 3. Anton Paar rheometer

Calculations on the interaction of ultrasound with fluid located in the channels, cracks, capillaries, and pores of the bottomhole zone were considered for a one-dimensional plane ultrasonic wave, whose length $\lambda$ substantially exceeds the radius of those channels [12].

When describing the propagation of an acoustic wave in a solidstate material of the formation structure, it is necessary to use the elasticity equation, taking into account its viscosity and thermal conductivity, for the vector $\mathrm{U}$ of the corresponding shear:

$$
\begin{gathered}
\rho_{0} \partial_{t t}^{2} U=\left[\rho_{0}\left(c_{l}^{2}-c_{t}^{2}\right)+\zeta_{0}+\frac{\eta_{0}}{3}\right] \nabla \operatorname{div} U+ \\
\left(\rho_{0} c_{t}^{2}+\eta_{0}\right) \Delta U-\frac{E_{\alpha}}{3(1-2 \sigma)} \nabla T
\end{gathered}
$$

and the thermal conductivity equation in solid bodies for temperature:

$$
C_{V} \partial_{t} T+\frac{C_{P}-C_{V}}{\alpha} \partial_{t} \operatorname{div} U=\chi * \Delta T
$$

where $\rho_{0}$ is the density of the material, $c_{1}$ and $c_{t}$ are the velocities of longitudinal and transverse vibrations in a solid body; $\mathrm{E}$ and $\sigma$ are the elastic moduli; $\mathrm{C}_{\mathrm{P}}$ and $\mathrm{C}_{\mathrm{V}}$ are the heat capacities at constant pressure and volume, respectively; $\zeta_{0}$ and $\eta_{0}$ are the coefficients of the first and second viscosity; $\chi$ is the coefficient of thermal conductivity; $\alpha$ is the coefficient of thermal expansion of the material.

In order to determine the flow rate of the fluid Q, one can write the following formula ( $\varphi$ is the azimuthal variable in a cylindrical coordinate system):

$$
Q=\rho \int_{0}^{R} r d r \int_{o}^{2 \pi} d \varphi v=\frac{\pi R^{4} \rho}{8 \mu}\left\{\frac{\Delta p}{L}+\rho \xi^{2} \omega^{2} \kappa\right\}
$$

As can be seen from (3), ultrasound effectively increases the fluidity of the fluid, thereby enhancing its flow rate. Dividing the flow into spontaneous and forced, associated with ultrasonic processing, one can write expression (3) in the following forms:

$$
\begin{aligned}
& Q=Q_{0}+Q_{S} \\
& Q_{0}=\frac{\pi R^{4} \rho}{8 \mu} \frac{\Delta p}{L} \\
& Q_{S}=\frac{\pi R^{4} \rho^{2} \omega^{2} \kappa}{8 \mu}
\end{aligned}
$$

Formula (6) can be rewritten in a different manner, by introducing the effective viscosity $\mu_{\mathrm{eff}}$, taking into account the effect of ultrasound in the form that allows us to preserve the standard form of the Poiseuille equation, in which $\mu_{\text {eff }}$ appears instead of $\mu$ :

$$
Q=Q_{0} \frac{\mu}{\mu_{e f f}}
$$

$$
\mu_{e f f}=\frac{\mu}{1+\frac{Q_{s}}{Q_{0}}}
$$

It can be seen from (8) that the effective viscosity is always less than the value that is characteristic of the undisturbed fluid, i.e. $\mu_{\text {eff }}<\mu$. This indicates an increase in fluid transfer in the presence of ultrasound [12].

As a result of the laboratory experiment, the viscosity during ultrasonic processing showed a significant decrease to $30 \%$ 
from the initial value of $138 \mathrm{MPa}^{*}$ s. All measurements were carried out under standard conditions: $\mathrm{P}=1$ atm., $\mathrm{T}=25^{\circ} \mathrm{C}$.

Fig. 4 shows the dependence of viscosity on the processing time.

\section{Dependence of viscosity on processing time}

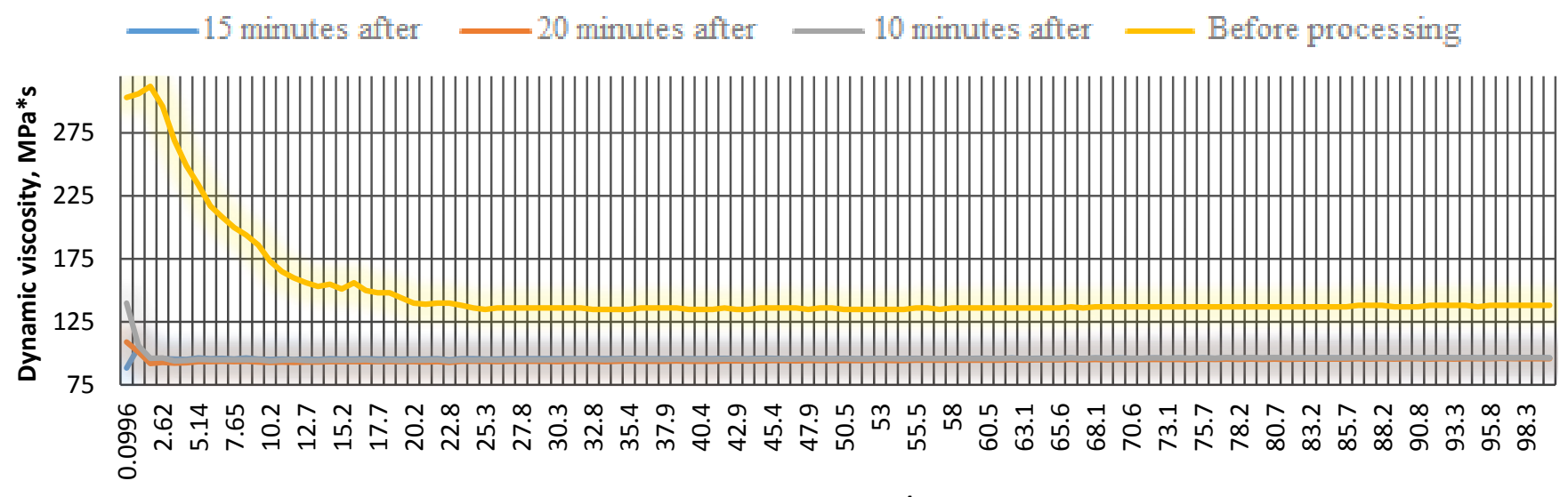

Shear rate, $1 / \mathrm{s}$

Fig. 4. Dependence of viscosity on processing time

The temperature during processing was measured with an accuracy class 1 thermometer and an accuracy class 2 pyrometer. According to measurements, an increase in temperature is observed up to 15 minutes of processing, followed by insignificant changes. Fig. 5 shows temperature changes due to wave action.

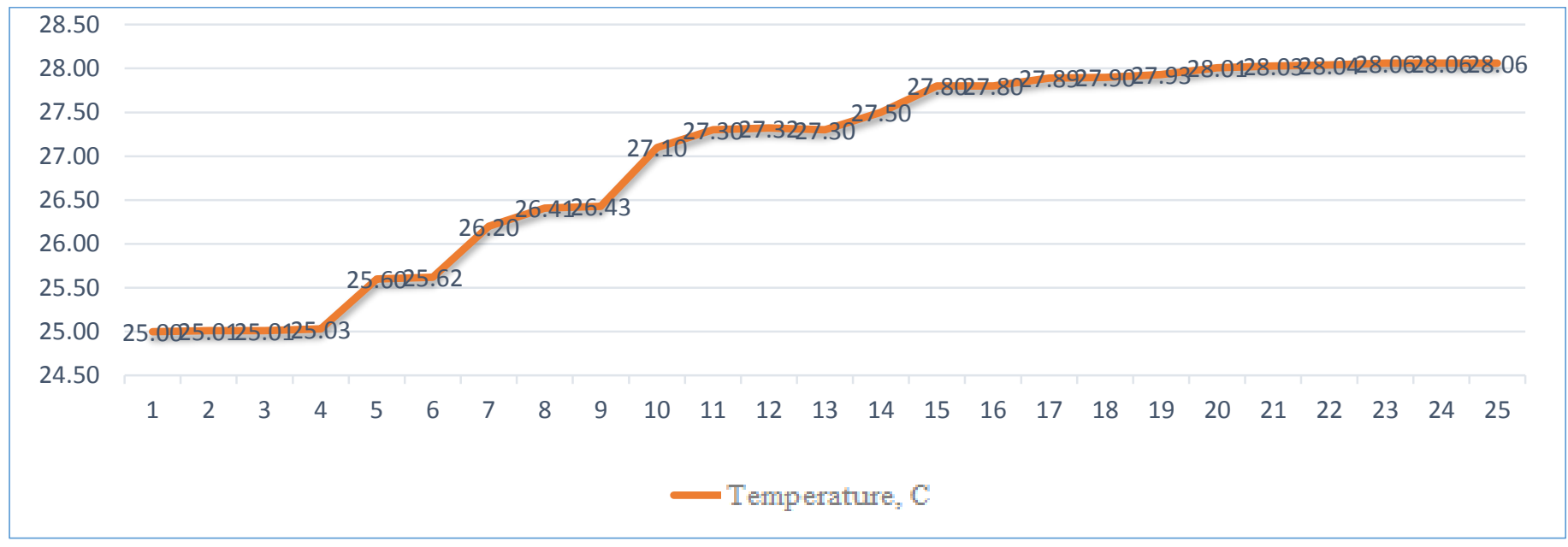

Fig. 5. Dependence of temperature changes due to wave action

The experiment analyzed the viscosity of well oil with a $50 \%$ water cut. Before processing, its value was $675 \mathrm{MPa}^{*}$ s. After processing, the oil and water phases were separated at a temperature of $25^{\circ} \mathrm{C}$, and an oil emulsifier was added to prevent further phase separation.
Fig. 6 shows the dependence of the viscosity of oil with a $50 \%$ water cut. 


\section{Dependence of the viscosity of oil with a $\mathbf{5 0 \%}$ water cut}

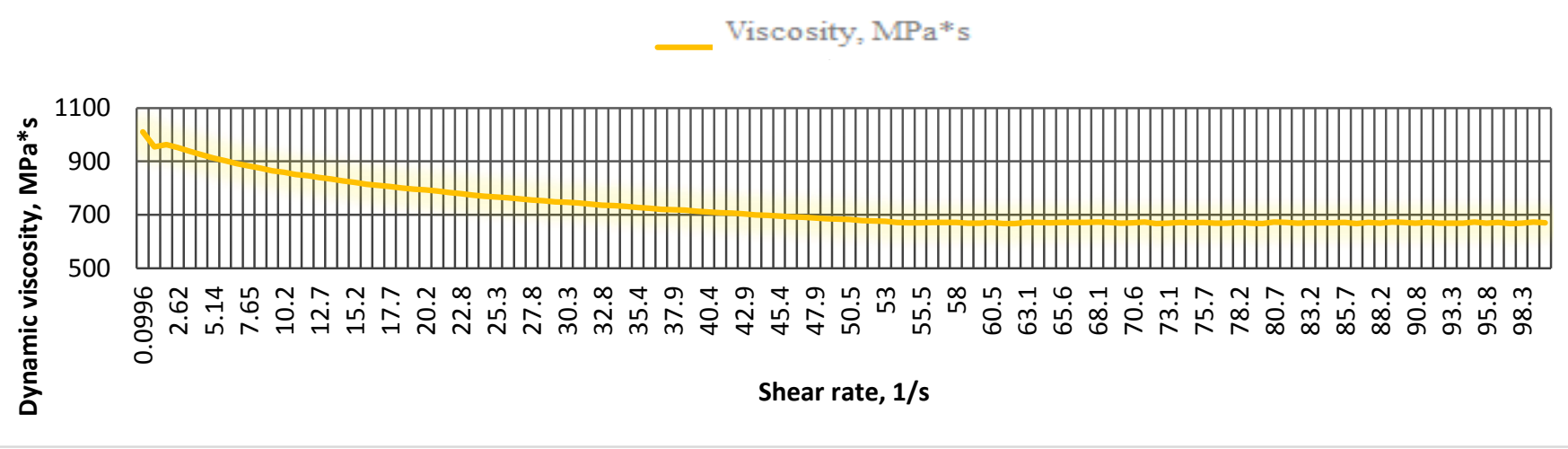

Fig. 6. Dependence of the viscosity of oil with a $50 \%$ water cut

Based on the laboratory experiment data, a sector model was built. Figs. 7-10 show the constructed hydrodynamic model.

The following information was used as the input for a detailed correlation of well sections:

- interpreted GIS curves: DEPT, SP, CALI, MNOR, MINV, LL3, CILD, RT, GR, NGLD, ASP, DGR, VCL, PHIT, PHIE, SOIL, SODW, PRMB, CSAT, COLL;

- GIS interpretation results table;

- GIS interpretation tablets (hydrodynamic well research).

Using the above data, a detailed correlation of well sections was carried out according to an independent system of transverse profiles along and across the object. In order to identify the stratification sequence through the primary monitoring of clay layers, the correlation was carried out from bottom to top according to the sequence of layers.

Based on the interpreted seismic surface of an object and the GIS well data, structural surfaces were constructed along the top and bottom of the main horizon and the bundles separating it. Using the obtained structural surfaces, the structural framework of the model was built.

At each stage of creating a structural model, control was carried out over the consistency of the initial data and the construction results. Control over the non-intersection of surfaces was carried out both using built-in functions and visually on the profiles.

A properly constructed three-dimensional grid is the basis for constructing a correct geological model. To build a structural framework, a modeling area (boundary) with a dimension of $25 \times 25 \times 0.2$ was created. When choosing the grid sizes, power maps were calculated vertically between the surfaces of the top and bottom of the bundles. Based on the distribution of values on these maps, the number of cells vertically was chosen in such a way so that the cell size was on average about 0.2 meters. Such grid sizes are most optimal when constructing geological models, because on the one hand, they are comparable to the sampling rate of the GIS curves, and on the other hand, they give an acceptable, from the point of view of calculation time, number of cells.

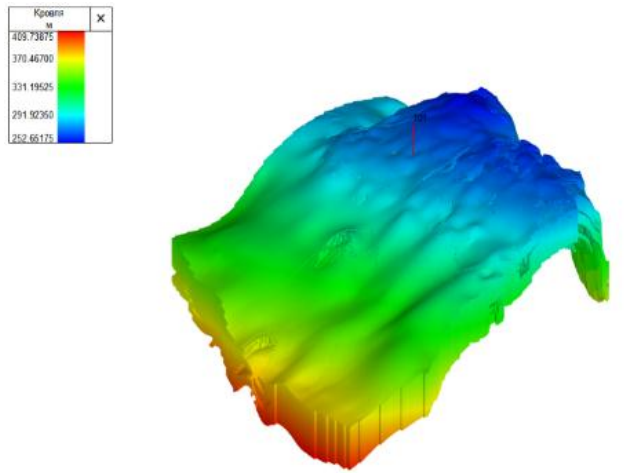

Fig. 7. Structural map of the formation top

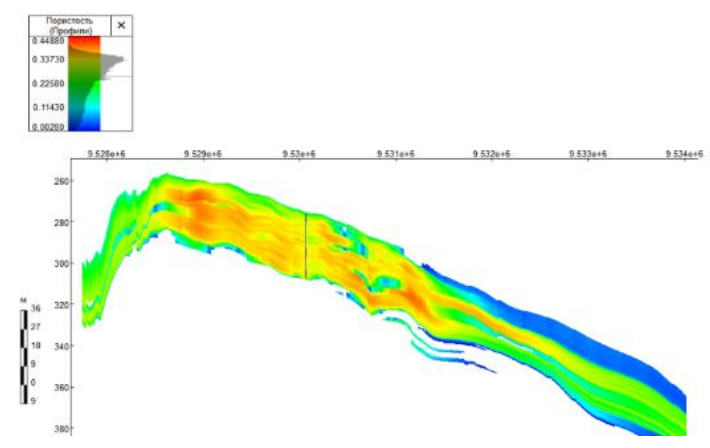

Fig. 8. Transverse profile of the porosity cube
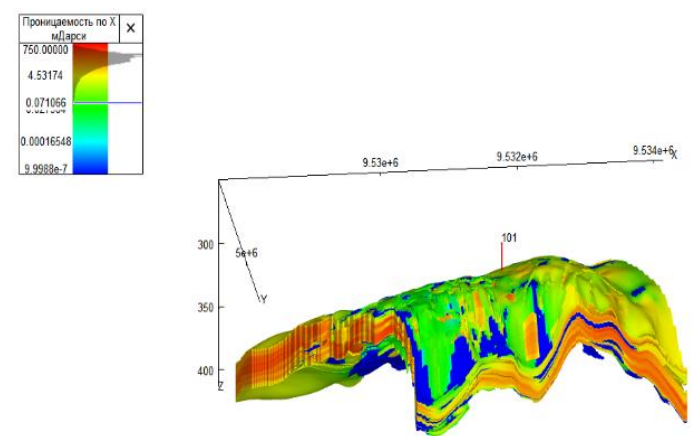

Fig. 9. The horizontal permeability cube 


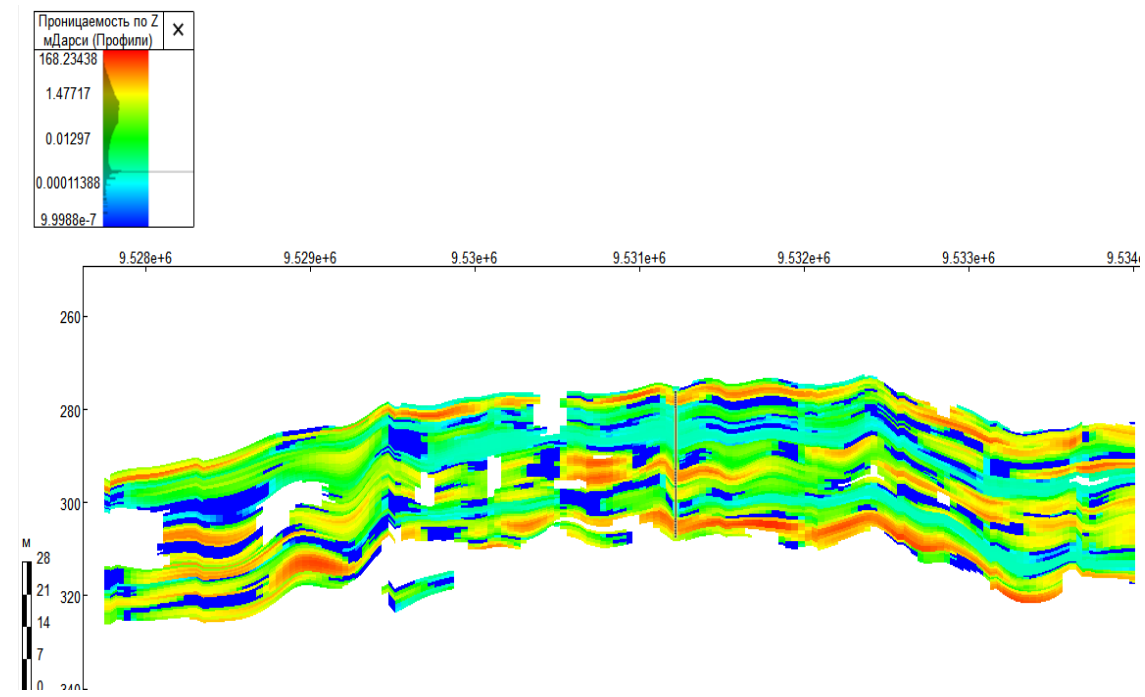

Fig. 10. Longitudinal profile of the vertical permeability cube

\section{Production Profile for Well No. 101}

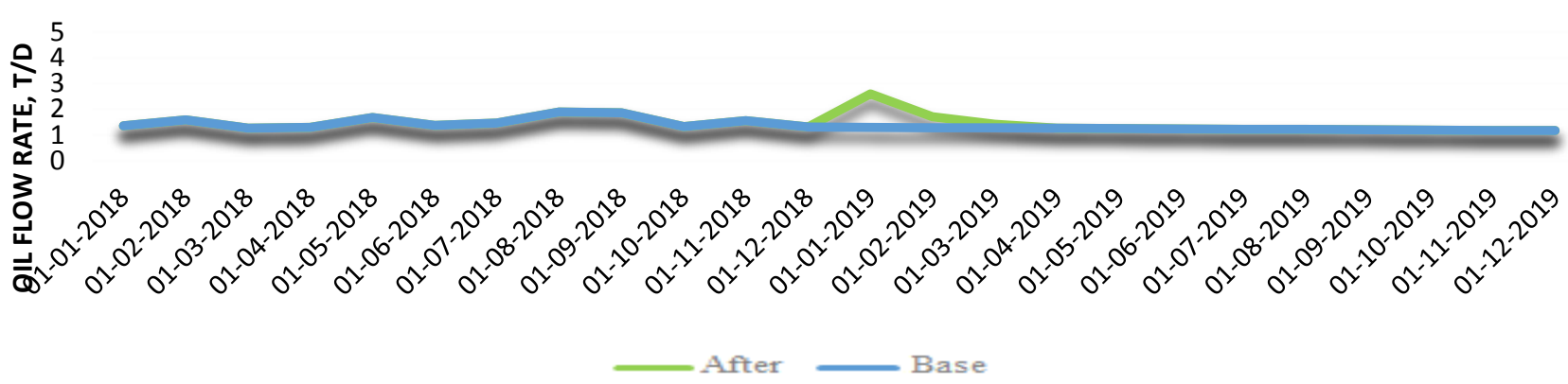

Fig. 11. Hydrodynamic modeling results

According to hydrodynamic modeling results, the accumulated additional production rate amounted to 53.75 tons from one processing in 90 days, and the average daily increase was 0.59 tons/day.

\section{DISCUSSION}

This paper presented a review of existing waveform technologies to reduce oil viscosity. The authors conducted a laboratory experiment to reduce viscosity, built a hydrodynamic model to determine its effectiveness for processing a single well, and built a model using COMSOL Multiphysics software.

Based on the experimental results, it was established that after ultrasonic processing, oil was heated by $3-4^{\circ} \mathrm{C}$, as a result of which a decrease in viscosity by $30 \%$ was observed. During these works, the effect of phase separation was also observed without adding a demulsifier without additional heating.

According to the laboratory experiment, acoustic treatment should be carried out on low-flow wells with low water cut.
Within the framework of this work, a sectoral geological and hydrodynamic model was built, and using the obtained data, a forecast calculation for one year was carried out. Based on the calculation results, an additional oil production of 53.75 tons was obtained for one well.

\section{CONCLUSIONS}

For the effective application of this method to reduce oil viscosity, it is necessary to carefully select the optimal mode of wave processing. When improving existing technologies, this method in combination with others can be used to develop hard-to-recover reserves.

A firm-specific, patented technology is a highly effective way to clean the bottom-hole zone of typical contaminants such as resin, paraffin and salt deposits, thereby significantly increasing the oil flow to the wellbore. This technology does not involve the use of any chemicals and allows the well to be in oil production mode during the treatment process.

The use of this technology within the framework of pilot 
production in the Republic of Kazakhstan showed a positive effect on enhancing the efficiency of the water pressure regime of well operation, as well as increasing the oil recovery coefficient.

With regard to the results of this work, it is recommended to use the technology of stimulation of the bottom-hole zone with ultrasound in wells with high viscosity values, as well as with a large difference in the viscosities of produced and injected fluids under water pressure conditions.

\section{ACKNOWLEDGEMENTS}

The authors would like to express their gratitude to the Ministry of Education and Science of the Republic of Kazakhstan and Satbayev University (Almaty, Kazakhstan) for supporting this study through a research management grant under the Competition for Grant Funding for Scientific and Technical Projects for 2018-2020, AR05130483 "Scientific and Technical Foundations for Reducing Viscosity of Kazakhstani Oils, Providing a Significant Increase in Oil Recovery", and the Calculation and Implementation of Scientific Work on the Project Objectives, led by Gulnaz Zhaksylykovna Moldabayeva, Doctor of Engineering, Associate Professor at Department of Petroleum Engineering, Satbayev University.

\section{REFERENCES}

[1] Mohammadian E, Junin R, Rahmani O Idris AK. Effects of sonication radiation on oil recovery by ultrasonic waves stimulated water-flooding. Elsevier Ultrasonics. 2013;53:607-614.

[2] Agi A, Junin R, Shirazi R, Afeez G, Yekeen N. Comparative study of ultrasound assisted water and surfactant flooding. Journal of King Saud University Engineering Sciences. 2019;31(3):296-303.

[3] Centre of Ultrasonic Technologies, Moscow, Russia. http://cut-service.ru/wpcontent/uploads/2016/09/AWS-presentation-rus.pdf

[4] Hamidi H, Mohammadian E, Junin R, Rafati R, Manan M, Azdarpour A, Junid M. A technique for evaluating the oil/heavy-oil viscosity changes under ultrasound in a simulated porous medium. Elsevier Ultrasonics. 2014;54:655-662.

[5] Volkova GI, Prozorova IV, Anufriev RV, Yudina NV, Mullakaev MS, Abramov VO. Ultrasonic treatment of oils for improvement of viscosity-temperature characteristics. Oil Refining and Petrochemistry. 2012;2: 3-6.

[6] Wang Zh, Zeng J, Song H, Li F. Research on ultrasonic excitation for the removal of drilling fluid plug, paraffin deposition plug, polymer plug and inorganic scale plug for near - well ultrasonic processing technology. 2017;36:162-167.

[7] Kookueva VV. Trends of financing sustainable development of rural areas in Russia. Life Science
Journal. 2014;11(6s):310-314. http://www.lifesciencesite.com/lsj/life1106s/062_2425 7life1106s14_310_314.pdf

[8] Prachkin VG, Mullakaev MS, Asylbaev DF. Increase of well productivity by means of acoustic action on highviscosity oil in channels of well bottomhole zone. Chemical and Petroleum Engineering. 2014;9:15-19.

[9] Mergentay A, Kulov DB, Bekembayeva GS, Koikov VV, Omarkulov BK, Mussabekova SA. The analysis of working load of general practitioners in the Republic of Kazakhstan. Research Journal of Pharmacy and Technology. 2019; 12(5), 2283-2288.

[10] Nurmambetov KE, Nurmambetova DE, Nusupbekova DA. Pat. 27064, Republic of Kazakhstan, E21B43/16. The resonance-wave method of increasing the oil recovery coefficient. 2013. http://kzpatents.com/5ip27064-rezonansno-volnovojj-sposob-povysheniyakoefficienta-izvlecheniya-nefti.html

[11] Evdokimov IN, Eliseev NYu, Fesan AA. The change of rheological properties of high viscosity of the structured oil when ultrasonic processing. Memoirs of the Faculty of Physics. 2014;6:146315.

[12] Prachkin VG. Intensification of oil production by a combined method based on ultrasonic treatment. Doctoral dissertation. Ufa State Petroleum Technological University, 2018. 